\title{
How microbes of an Antarctic lake have adapted to the polar light cycle
}

Pratibha Panwar

Michelle A. Allen

Timothy J. Williams

Alyce M. Hancock

Sarah Brazendale

James Bevington

Simon Roux

David Paez-Espino

Stephen Nayfach

Maureen Berg

Frederik Schulz

Amy Chen

Marcel Huntemann

Nicole Shapiro

Nikos Kyrpides

Tanja Woyke

Emiley A. Eloe-Fadrosh

Ricardo Cavicchioli

\section{Video Byte}

Keywords: biosphere, Earth, microbes, Ace Lake, Antarctica, Southern Ocean, biogeochemical cycles, nutrient cycles, metagenomes, polar light cycle, green sulfur bacteria, cyanobacteria, Chlorobium, chemolithoautotrophic carbon-fixation, Microbiome

Posted Date: November 11th, 2020

DOl: https://doi.org/10.21203/rs.3.rs-106065/v1

License: (a) (i) This work is licensed under a Creative Commons Attribution 4.0 International License. Read Full License 


\section{Abstract}

Life in cold environments dominates Earth's biosphere, where microbial activity plays a large role in biogeochemical cycles. 120 metagenomes from Ace Lake in East Antarctica were analyzed for a seasonal cycle and four summers over 10 years to determine how the polar light cycle affects microbialdriven nutrient cycles. The two most abundant taxa found were green sulfur bacteria (GSB) and cyanobacteria, both of which are highly influenced by light availability. Interestingly, the abundance of one important GSB member, Chlorobium, dropped significantly in winter before rebounding back to high levels in the spring. Although viruses specific for these microbes were abundant, the negative impact of viral infection on host growth appeared to be limited. Unlike other microbes in the Southern Ocean that use chemolithoautotrophic carbon-fixation, the microbes of Ace Lake have evolved to rely on photosynthesis and can generate enough biomass and remineralize enough nutrients to sustain themselves between two rounds of sunlight-driven summer activity. 